\title{
Biological Basis of Sex Differences in the Propensity to Self-administer Cocaine
}

\author{
Ming Hu', Hans S Crombag', Terry E Robinson ${ }^{1,2}$ and Jill B Becker*,1,2,3 \\ 'Psychology Department, University of Michigan, Ann Arbor, MI, USA; ${ }^{2}$ Neuroscience Program, University of Michigan, Ann Arbor, MI, USA; \\ ${ }^{3}$ Reproductive Sciences Program, University of Michigan, Ann Arbor, MI, USA
}

\begin{abstract}
Women are at greater risk for cocaine addiction than are men, and female rats similarly show a greater propensity to self-administer cocaine than do male rats. This could be due to the intrinsic sex differences in brain organization, to the activational effects of circulating gonadal hormones, or both. For example, estradiol enhances dopamine release in the striatum and nucleus accumbens, and facilitates the behavioral sensitization induced by repeated cocaine exposure. We report here that independent of circulating gonadal hormones, female rats acquire cocaine self-administration behavior more rapidly, and they self-administer more cocaine at a faster rate than do male rats. This indicates that there is an intrinsic difference between male and female subjects in the neural systems mediating drug-seeking behavior due to sexual differentiation of the brain. Furthermore, we find that the administration of estradiol to gonadectomized female subjects greatly facilitates the acquisition of cocaine self-administration. These data demonstrate that both intrinsic sex differences in brain organization and the actions of circulating estradiol contribute to increased vulnerability for cocaine use in female subjects.

Neuropsychopharmacology (2004) 29, 8 I -85, advance online publication, 3 September 2003; doi:I 0. I 038/sj.npp. I 30030 I
\end{abstract}

Keywords: estradiol; sex differences; cocaine; self-administration; dopamine and drug abuse

\section{INTRODUCTION}

Cocaine abuse by women has increased rapidly in the last decade. It is estimated that approximately $30 \%$ of the 1.8 million Americans who use cocaine are now women, and sex differences in the patterns of cocaine use and addiction are well documented. For example, women begin using cocaine at an earlier age than men; after first use they take less time to become addicted, they enter treatment at a younger age than men, and when they present for treatment, they have a more severe habit than men (Griffin et al, 1989; Kosten et al, 1993; Mendelson et al, 1999). Furthermore, cocaine cues induce more drug craving in female than male addicts (Robbins et al, 1999). It appears, therefore, that women are more vulnerable than men to psychostimulant drugs, during all phases of the addiction process (eg initiation, maintenance, and relapse; for a review, see Lynch et al, 2002).

Sex differences in cocaine self-administration behavior are also found in rodents. Much of the work has been carried out examining the differences between intact female

\footnotetext{
*Correspondence: Dr JB Becker, Psychology Department, Biopsychology Area, 525 East University, Ann Arbor, MI 48109-1 109, USA, Tel: + I 734763 4363, Fax: + I 734763 7480,

E-mail: jbbecker@umich.edu

Received 09 April 2003; revised 17 July 2003; accepted 22 July 2003 Online publication: I August 2003 at http://www.acnp.org/citations/ NPP080 I0303 I55/default.pdf
}

and male rats where there are sex differences in acquisition, regulation, and reinstatement of cocaine self-administration behavior (Roberts et al, 1989; Lynch et al, 1999, 2000). Female rats are also more sensitive to the psychomotor activating effects of psychostimulants than are male rats, and with repeated drug treatment they show greater psychomotor sensitization (Robinson, 1984; $\mathrm{Hu}$ et al, 2003). The brain concentrations of cocaine after systemic administration are comparable for male and female rats, so pharmacokinetic sex differences do not account for the behavioral differences (Bowman et al, 1999).

The observed phenomena of sex differences in cocaine addiction in humans or self-administration behavior in rats do not address the biological basis of this sex difference. Furthermore, these observations do not address how the hormones of the menstrual/estrous cycle might modulate the subjective effects of cocaine, or why women continue to be at risk for cocaine addiction after cessation of their menstrual cycle, which can occur with chronic cocaine use (Mello, 1995). There are two possible (not mutually exclusive) biological mechanisms mediating the sex differences reported. First, sexual differentiation of the brain during development could produce sex differences in the adult brain that persist independent of circulating gonadal hormones in adulthood. Alternatively, in adults, circulating gonadal hormones could act on brain systems that mediate drug reward to modulate the actions of drugs. It is also possible that gonadal hormones act on a sexually dimorphic 
brain, so that both of these mechanisms are involved. To determine if intrinsic sex differences influence cocaine selfadministration behavior, we studied female and male rats gonadectomized as adults, in which the influence of circulating gonadal hormones is removed. To determine if circulating estradiol influences cocaine self-administration behavior, we studied the effects of exogenous estradiol treatments in gonadectomized female rats.

\section{MATERIALS AND METHODS}

\section{Animals}

Male and female adult Sprague-Dawley rats weighed $275-300 \mathrm{~g}$ at the beginning of the experiment (Harlan Sprague-Dawley, Indianapolis, IN). Animals were housed individually under a 14:10 reverse light/dark cycle at a constant temperature of $20-21^{\circ} \mathrm{C}$, and received a phytoestrogen-free rodent chow (2014 Teklad Global 14\% protein rodent maintenance diet, Harlan rat chow, Madison, WI), and water was continuously available. All the procedures were carried out according to a protocol approved by the University of Michigan Use and Care of Animals Committee.

\section{Surgery}

Approximately 1 week after arrival, all rats underwent gonadectomy or sham surgery under isoflurane anesthesia as described previously (Hu et al, 2003). After 4 days, female rats underwent daily examination of the vaginal epithelium by vaginal lavage for 10 consecutive days to ensure cessation of cycling and male rats were handled as a control.

Approximately 2-3 weeks after gonadectomy or sham surgery, rats were prepared with indwelling intravenous jugular catheters connected to a backport. Jugular catheter construction and implantation were based on previously described procedures (Weeks, 1972; Kalivas et al, 1993; Crombag et al, 2000). Briefly, catheters were constructed by gluing silastic tubing $(0.51 \mathrm{~mm}$ ID, $0.94 \mathrm{~mm}$ OD; Dow Corning, City, State) to an external guide cannula. The cannulae were then glued to polypropylene mesh with cranioplastic cement. Rats were anesthetized with a combination of ketamine $(100 \mathrm{mg} / \mathrm{kg})$, xylazine $(1.5 \mathrm{mg} /$ $\mathrm{kg})$, and acepromazine $(0.8 \mathrm{mg} / \mathrm{kg})$. The free end of the silastic tubing was inserted into the right jugular vein and secured with 4.0 silk sutures around the venous tissue. The catheters exited dorsally on the animal's back. Dummy stylets were inserted into the catheters when rats were not connected to infusion pumps. Catheters were flushed twice daily with $0.1 \mathrm{ml}$ heparinized saline $(30 \mathrm{U} / \mathrm{ml}$, in $0.9 \%$ sterile saline buffered at $\mathrm{pH}=7.4)$ and a $0.1 \mathrm{ml}$ gentamicin solution $(50 \mathrm{mg} / \mathrm{ml})$ to prevent occlusions and to circumvent microbial buildup in the catheter. For each selfadministration session, catheters were flushed with $0.1 \mathrm{ml}$ of heparin before sessions began and with $0.1 \mathrm{ml}$ gentamicin after each session.

\section{Self-administration}

At 5 days after recovery from surgery, rats were placed into standard operant chambers (Med Associates) and were allowed to nose poke to obtain an i.v. infusion of cocaine on an FR1 schedule of reinforcement during a 1-h session each day. Animals were not pretrained to nose poke or primed. Animals were connected to an infusion syringe and tethered via a steel cable to a swivel, which was mounted on a counterbalanced arm. This allowed the animal to move freely in the test cage. Each response in the active hole produced a compound stimulus consisting of a white stimulus light, a tone $(85 \mathrm{~dB})$, and an intravenous injection of $50 \mu \mathrm{l}$ of cocaine $\mathrm{HCl}$ in saline delivered over $2.8 \mathrm{~s}$. The compound stimulus occurred simultaneously with the cocaine injection and was followed by a $5 \mathrm{~s}$ time out period, during which time further responses had no programmed consequences but nose pokes were recorded. Nose pokes in the inactive hole were also recorded, but had no programmed consequences.

To determine the cocaine dose used in this study, we conducted a pilot study to compare female rats that were ovariectomized (OVX) $(n=7)$ vs OVX female rats treated with $5.0 \mu \mathrm{g}$ of estradiol benzoate $(\mathrm{E} ; \mathrm{OVX}+\mathrm{E})(n=7)$. During the first 5 days of self-administration testing, $0.2 \mathrm{mg} / \mathrm{kg} /$ injection of cocaine was available, and during the second and third 5 days of testing, $0.3 \mathrm{mg} / \mathrm{kg} /$ injection of cocaine was available. Under these conditions, neither group reliably self-administered cocaine with the $0.2 \mathrm{mg} / \mathrm{kg} /$ injection dose. However, when $0.3 \mathrm{mg} / \mathrm{kg}$ cocaine was available the $\mathrm{OVX}+\mathrm{E}$ group showed much more robust self-administration behavior than the OVX group $(p<0.001$; data are not shown, but the response at $0.3 \mathrm{mg} / \mathrm{kg}$ was similar to the results depicted in Figure 1). Given that there was no effect of hormone treatment, and that neither group acquired self-administration behavior at the $0.2 \mathrm{mg} / \mathrm{kg} /$ injection dose, we tested $0.3,0.4$, and $0.5 \mathrm{mg} / \mathrm{kg}$ cocaine doses in these experiments.

Four groups of rats were given the opportunity to selfadminister cocaine: (1) OVX $(N=8)$; (2) males that were castrated (Cast; $N=8$ ); (3) gonadally intact but sham operated males (Sham; $N=8)$; and (4) OVX + E $(N=9)$. At $30 \mathrm{~min}$ prior to each self-administration session, $\mathrm{OVX}+\mathrm{E}$ rats received an injection of $5.0 \mu \mathrm{g} \mathrm{E}$ in $0.1 \mathrm{ml}$ peanut oil (s.c.) and OVX, Cast, and Sham rats received $0.1 \mathrm{ml}$ peanut oil (s.c.). For the first 5 days of testing, responses at the 'active' hole resulted in the administration of $0.3 \mathrm{mg} / \mathrm{kg} / \mathrm{infusion}$ of cocaine $\mathrm{HCl}$. The animals were then given 2 days off, during which time hormones were not administered. Then, during the next 5 days of testing, the dose was raised to $0.4 \mathrm{mg} / \mathrm{kg} /$ infusion. After another 2 days off, the dose was raised to $0.5 \mathrm{mg} / \mathrm{kg} /$ infusion for the last 5 days of testing. This procedure allowed us to determine the effect of dose on the acquisition of cocaine self-administration behavior as a function of treatment condition.

The rationale for 5 days of $E$ treatment followed by 2 days without $\mathrm{E}$ was to prevent dopamine receptor supersensitivity, which develops with chronic elevation of serum estradiol (Di Paolo et al, 1981). Serum estradiol concentrations produced by this dosing regimen at the time of behavioral testing were determined using a sensitive immunofluorimetric assay in a separate group of animals (England et al, 2002). At $30 \mathrm{~min}$ post-E, serum concentrations of estradiol increased from the OVX concentration of $23.6 \pm 2.5$ to $154.8 \pm 25.8 \mathrm{pg} / \mathrm{ml}$ (mean $\pm \mathrm{SEM}, \quad N=5 /$ group). At $1 \mathrm{~h}$ post-E the serum concentrations were 
$184.5 \pm 38.3 \mathrm{pg} / \mathrm{ml}$ and $24 \mathrm{~h}$ after treatment concentrations had decreased to $109.5 \pm 19.2 \mathrm{pg} / \mathrm{ml}$. Concentrations of serum estradiol achieved on the fourth or fifth day of treatment at $1 \mathrm{~h}$ post-E were not significantly different from the values reported for $1 \mathrm{~h}$ post-E on day one, indicating no significant accumulation of $\mathrm{E}$ with this dosing regimen. These values are all in the physiological range for estradiol in the proestrous rat (Butcher et al, 1974; Henderson et al, $1977 \mathrm{a}, \mathrm{b})$. Thus, at the time animals were tested each day, serum E concentrations were within the physiological range.

At the beginning and end of each week, the catheters were tested for patency by intravenously injecting $0.1 \mathrm{ml}$ of the short-acting Pentothal (thiopental sodium, $20 \mathrm{mg} / \mathrm{ml}$ in sterile water). Rats that did not become ataxic within $5 \mathrm{~s}$ were excluded from the analysis.

\section{Statistical Analysis}

All data were analyzed using the computer program Statview 4.5 for the Macintosh. Comparisons were made by analysis of variance (ANOVA) and subsequent post hoc comparisons with Bonferroni's $p$ to compensate for multiple comparisons. Groups were considered to be significantly different if $p<0.05$.

\section{RESULTS}

As shown in Table 1, OVX female rats treated with $5 \mu \mathrm{g}$ estradiol benzoate $30 \mathrm{~min}$ before self-administration testing $(\mathrm{OVX}+\mathrm{E})$ acquired cocaine self-administration (as defined by 3 days of responding at a rate of 10 responses in the $1 \mathrm{~h}$ session) in approximately 4 days. The OVX rats (treated with vehicle) reached the criterion approximately two test days later, and this was not significantly different from the OVX + E group (Table 1). The castrated (Cast) male and the intact male (Sham) groups acquired self-administration of cocaine after approximately 9 days. This was significantly later for both Cast and Sham than for the OVX and OVX $+\mathrm{E}$ groups $(p<0.01$; Table 1$)$.

Figure 1 shows the number of infusions of cocaine taken by rats in the OVX $+\mathrm{E}(N=9), \operatorname{OVX}(N=8)$, Cast $(N=8)$, and Sham $(N=8)$ groups across weeks of testing with increasing doses. During the first five sessions rats received $0.3 \mathrm{mg} / \mathrm{kg} /$ infusion, during the second five sessions they received $0.4 \mathrm{mg} / \mathrm{kg} /$ infusion, and during the last five sessions they received $0.5 \mathrm{mg} / \mathrm{kg} /$ infusion. ANOVA with repeated measures was conducted for data at each dose. At $0.3 \mathrm{mg} / \mathrm{kg} /$ infusion, there was a main effect of Group, $\mathrm{F}_{3,36}=20.90, p<0.0001$; an effect of Day of treatment, $\mathrm{F}_{4,12}=21.69, \quad p<0.001$; and a Group $\times$ Day interaction, $\mathrm{F}_{12,144}=5.01, p<0.001$. Post hoc pairwise comparisons indicated that $\mathrm{OVX}>$ Cast $(p<0.05)$ and that $\mathrm{OVX}+\mathrm{E}>$ all other groups $(p<0.001)$. At $0.4 \mathrm{mg} / \mathrm{kg} / \mathrm{infusion}$, there was a main effect of Group, $\mathrm{F}_{3,33}=7.224, p<0.001$; an effect of Day of treatment, $\mathrm{F}_{4,12}=3.167, p<0.02$; and no Group $\times$ Day interaction, $\mathrm{F}_{12,144}=0.814, p=0.635$. Post hoc pairwise comparisons indicated that OVX $>$ Cast $(p<0.001)$, OVX $>$ Sham $(p<0.004)$ and OVX $+\mathrm{E}>$ all other groups $(p<0.001)$. At $0.5 \mathrm{mg} / \mathrm{kg} /$ infusion, there was a main effect

Table I The Day that Animals Reached Criteria for Acquisition of Cocaine Self-administration

\begin{tabular}{lc}
\hline Group & Day reached criteria $^{\mathbf{a}}$ \\
\hline OVX+E & $4.20 \pm 0.0 .20^{\mathrm{b}}$ \\
OVX & $6.00 \pm 0.58^{\mathrm{b}}$ \\
Cast & $9.38 \pm 1.22$ \\
Sham males & $9.50 \pm 1.24$
\end{tabular}

a 10 infusions/h on three consecutive days, mean \pm SEM.

${ }^{b} \mathrm{OVX}$ and $\mathrm{OVX}+\mathrm{E}$ reached acquisition criteria significantly $(p<0.0 \mathrm{I})$ sooner than did the Cast and Sham groups $\left(F_{3,31}=9.55, p<0.001\right)$. There were no differences in day of acquisition in either experiment when OVX+E and OVX were compared.
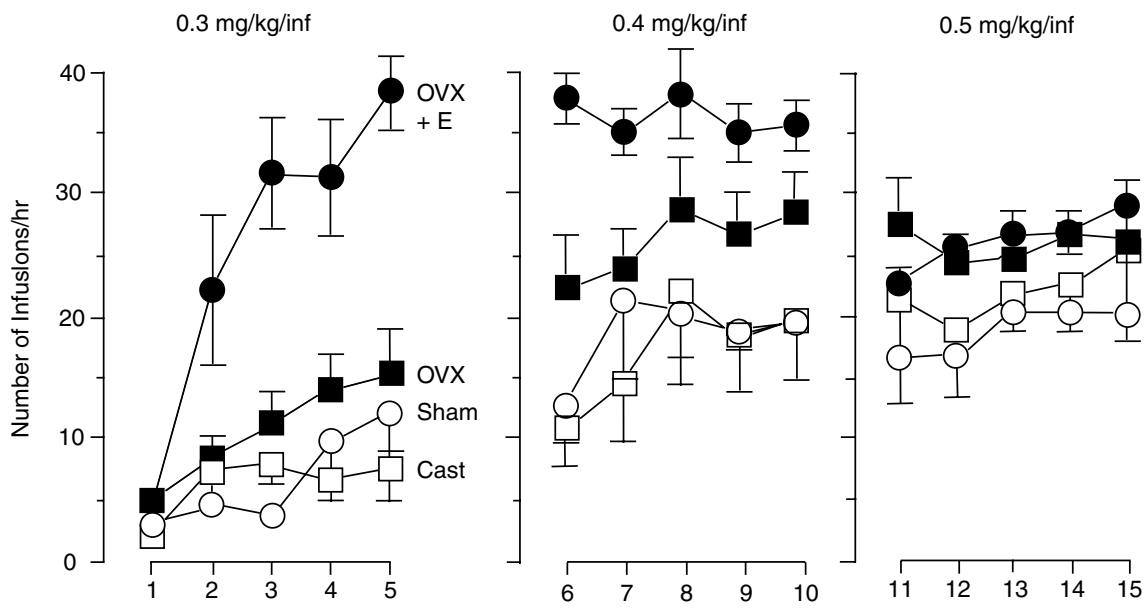

Self-Administration Session

Figure I Mean $( \pm S E M)$ number of infusions of cocaine per I h test session in the OVX $+E, O V X$, Cast, and Sham male groups. During the first five sessions rats received $0.3 \mathrm{mg} / \mathrm{kg} /$ infusion, during the second 5 days they received $0.4 \mathrm{mg} / \mathrm{kg} /$ infusion, and during the last 5 days they received $0.5 \mathrm{mg} / \mathrm{kg} /$ infusion. ANOVA with repeated measures was conducted for data at each dose. 
of Group, $F_{3,29}=4.152, p<0.015$; no effect of Day of treatment, $\mathrm{F}_{4,12}=2.018, \quad p<0.09$; and no Group $\times$ Day interaction, $\mathrm{F}_{12,116}=0.502, p=0.909$. Post hoc pairwise comparisons indicated that OVX $>$ Cast $(p<0.02)$, OVX $>$ Sham $(p<0.001)$, and OVX $+E>$ Cast and Sham groups $(p<0.001)$. Cast and Sham did not differ at any of the doses tested.

Figure 2 shows the mean ( \pm SEM) amount of cocaine received $(\mathrm{mg} / \mathrm{kg} / \mathrm{session})$ averaged over the three 5-day blocks of testing by rats in the OVX $+\mathrm{E}(N=9)$, OVX $(N=8)$, Cast $(N=8)$, and Sham $(N=8)$ groups. The analysis of variance of the mean amount of cocaine intake at each dose indicates that there was a main effect of Group, $\mathrm{F}_{3,29}=11.539, p<0.001$; an effect of dose, $\mathrm{F}_{2,6}=107.098$, $p<0.001$; and no Group X Week interaction, $\mathrm{F}_{6,59}=2.166$, $p=0.0594$. Subsequent ANOVA on each 5-day testing block indicated that at $0.3 \mathrm{mg} / \mathrm{kg} /$ infusion, the OVX group selfadministered more cocaine than did the Cast group $(p<0.04)$ and the OVX $+\mathrm{E}$ group self-administered more cocaine than the other three groups $(p<0.001)$. At $0.4 \mathrm{mg} /$ $\mathrm{kg}$ /infusion, the OVX group self-administered more cocaine than the Cast or Sham group $(p<0.001)$, and the OVX $+\mathrm{E}$ group self-administered more cocaine than OVX, Cast, and Sham groups $(p<0.001)$. At $0.5 \mathrm{mg} / \mathrm{kg} / \mathrm{infusion}$, the OVX and the $\mathrm{OVX}+\mathrm{E}$ groups self-administered more cocaine than the Cast or Sham group $(p<0.02-0.001)$.

\section{DISCUSSION}

Our results indicate that sex differences in the propensity to self-administer cocaine are due to at least two dissociable factors. First, the neural systems mediating cocaine selfadministration are sexually dimorphic. Independent of concurrent gonadal hormones in adulthood, OVX and Cast rats differ in the acquisition of cocaine self-administration. Second, in female rats, but not males, circulating gonadal hormones modulate drug-taking behavior. Estradiol promotes avid drug self-administration.

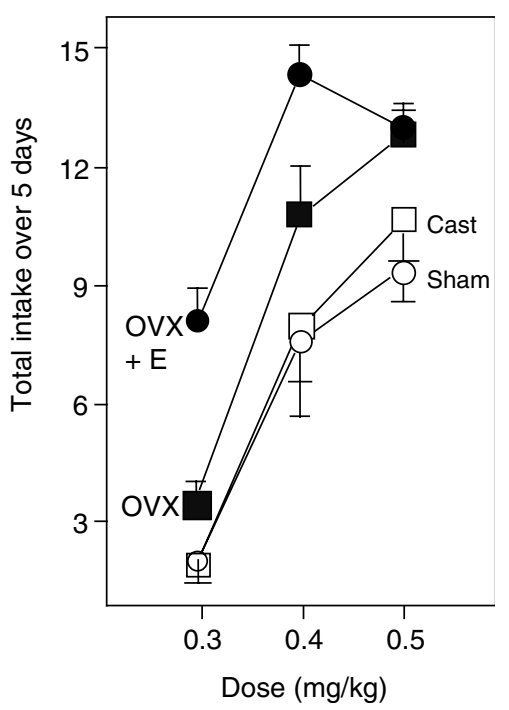

Figure 2 Mean $( \pm \mathrm{SEM})$ amount of cocaine received $(\mathrm{mg} / \mathrm{kg} / \mathrm{session})$ averaged over the three 5-day blocks of testing. ANOVA with repeated measures was conducted for data at each dose.
It is well known that early in development, testicular secretions exert effects on the nervous system that lead to sex differences in brain organization (Breedlove et al, 2002). There are also effects of exposure to gonadal hormones at puberty that contribute to sex differences in brain and behavior (Romeo et al, 2000; McEwen, 2001; Pellis, 2002). Whether neonatal and/or pubertal hormone secretions organize the neural systems that mediate drug-related behaviors is not known. However, sex differences in the morphology of embryonic mesencephalic dopamine neurons that are determined by the chromosomal sex (XX vs $\mathrm{XY}$ ) of an animal, rather than gonadal secretions, have been reported in mice and rats (Reisert et al, 1990; Kolbinger et al, 1991; Carruth et al, 2002). Thus, the organizational effects of gonadal hormones during development and/or genetically guided neurodevelopmental processes may lead to intrinsic sex differences in brain systems that mediate drug reward, such as the mesotelencephalic dopamine system, and thereby account for the sex differences in behavior reported here.

The idea that sex differences in the propensity to selfadminister cocaine are enhanced by activational effects of estradiol is well supported. Estradiol is known to influence many drug-related behaviors and facilitate the development of behavioral sensitization (Becker, 1999; Hu et al, 2003), which has been implicated in the transition to addiction (Robinson et al, 2000). Cocaine self-administration varies across the estrous cycle (Roberts et al, 1989), and high doses of estradiol facilitate cocaine self-administration (Lynch et al, 2001). Furthermore, estradiol increases stimulated dopamine release in caudate-putamen and nucleus accumbens (Becker, 1999), enhances dopamine reuptake in nucleus accumbens (Thompson, 1999), influences striatal dopamine receptor density (Di Paolo et al, 1981), and rapidly shifts striatal D2 dopamine receptors from high- to low-affinity states (Levesque et al, 1988). Given that these mesotelencephalic dopamine systems are thought to mediate psychostimulant-induced behavioral sensitization and reward (Wise, 1987; Robinson et al, 2000), it is likely that the ability of estradiol to facilitate dopaminergic activity contributes to its enhancement of cocaine self-administration behavior.

In this study, we did not find a difference between Sham and Cast rats in the acquisition of cocaine self-administration at any dose (Figure 1). These results are consistent with previous studies in which there is no enhancement of sensitization to amphetamine in Cast males when testosterone was replaced (Forgie et al, 1994). There is also no significant difference between Cast and Sham males in sensitization to cocaine as indicated by cocaine-induced rotational behavior with repeated treatments of 5,10 , or $20 \mathrm{mg} / \mathrm{kg}$ ( $\mathrm{Hu}$ et al, 2003). Therefore, testicular hormones (ie neither testosterone nor testosterone aromatized to estradiol) do not appear to play a role in sensitization to psychomotor stimulants or in cocaine self-administration.

In conclusion, the intrinsic sex difference and the effects of circulating estradiol on cocaine self-administration behavior described here may be related to the growing evidence for sex differences in drug use and abuse in humans discussed above. Furthermore, the relative role of circulating estradiol $v s$ intrinsic sex differences may vary depending on the stage in the addiction process. For 
example, the effects of estradiol might be especially important in facilitating the initial acquisition of a cocaine habit, but with sustained use, cocaine can disrupt and even block the normal menstrual cycle (Mello, 1995), which would lead to decreased levels of circulating estradiol. However, in such women, an intrinsic sex difference in brain organization may continue to render them vulnerable. It will be very important in future studies to delineate the exact neurobiological mechanisms responsible for sex differences in drug-related behaviors, at different phases of the addiction cycle, because these sex differences may require the development of sex-specific strategies for intervention and treatment.

\section{ACKNOWLEDGEMENTS}

These studies were supported by a grant from the USPHS National Institute on Drug Abuse DA12677 to JBB. TER was supported by a Drug Abuse Senior Scientist Award K05 DA00473.

\section{REFERENCES}

Becker JB (1999). Gender differences in dopaminergic function in striatum and nucleus accumbens. Pharmacol Biochem Behav 64: 803-812.

Bowman BP, Vaughan SR, Walker QD, Davis SL, Little PJ, Scheffler NM et al (1999). Effects of sex and gonadectomy on cocaine metabolism in the rat. J Pharmacol ExpTher 290: 1316-1323.

Breedlove SM, Hampson E (2002). Sexual differentiation of the brain and behavior. In: Becker JB, Breedlove SM, Crews D, McCarthy MM (eds). Behavioral Endocrinology. MIT Press: Cambridge, MA. pp 75-115.

Butcher RL, Collins WE, Fugo NW (1974). Plasma concentration of $\mathrm{LH}, \mathrm{FSH}$, prolactin, progesterone and estradiol-17- $\beta$ throughout the 4-day estrous cycle of the rat. Endocrinology 94: 1704-1708.

Carruth LL, Reisert I, Arnold AP (2002). Sex chromosome genes directly affect brain sexual differentiation. Nat Neurosci 5: 933-934.

Crombag HS, Badiani A, Maren S, Robinson TE (2000). The role of contextual versus discrete drug-associated cues in promoting the induction of psychomotor sensitization to intravenous amphetamine. Behav Brain Res 116: 1-22.

Di Paolo T, Poyet P, Labrie F (1981). Effect of chronic estradiol and haloperidol treatment on striatal dopamine receptors. Eur J Pharmacol 73: 105-106.

England BG, Parsons GH, Possley RM, McConnell DS, Midgley AR (2002). Ultrasensitive semiautomated chemiluminescent immunoassay for estradiol. Clin Chem 48: 1584-1586.

Forgie ML, Stewart J (1994). Sex difference in amphetamineinduced locomotor activity in adult rats: role of testosterone exposure in the neonatal period. Pharmacol Biochem Behav 46: 637-645.

Griffin ML, Weiss RD, Lange U (1989). A comparison of male and female cocaine abuse. Arch Gen Psychiatry 46: 122-126.

Henderson SR, Baker C, Fink G (1977a). Effect of oestradiol-17beta exposure on the spontaneous secretion of gonadotrophins in chronically gonadectomized rats. J Endocrinol 73: 455-462.

Henderson SR, Baker C, Fink G (1977b). Oestradiol-17 $\beta$ and pituitary responsiveness to luteinizing hormone releasing factor in the rat: a study using rectangular pulses of estradiol-17 $\beta$ monitored by non-chromatographic radioimmunoassay. $J$ Endocrinol 73: 441-453.

$\mathrm{Hu} \mathrm{M}$, Becker JB (2003). Effects of sex and estrogen on behavioral sensitization to cocaine in rats. J Neurosci 23: 693-699.
Kalivas PW, Duffy P (1993). Time course of extracellular dopamine and behavioral sensitization to cocaine 0.1. Dopamine axon terminals. J Neurosci 13: 266-275.

Kolbinger W, Trepel M, Beyer C, Pilgrim C, Reisert I (1991). The influence of genetic sex on sexual-differentiation of diencephalic dopaminergic-neurons in vitro and in vivo. Brain Res 544: 349-352.

Kosten TA, Gawin FH, Kosten TR, Rounsaville BJ (1993). Gender differences in cocaine use and treatment response. J Subst Abuse Treat 10: 63-66.

Levesque D, Di Paolo T (1988). Rapid conversion of high into low striatal D2-dopamine receptor agonist binding states after an acute physiological dose of 17 beta-estradiol. Neurosci Lett 88: 113-118.

Lynch WJ, Carroll ME (1999). Sex differences in the acquisition of intravenously self-administered cocaine and heroin in rats. Psychopharmacology 144: 77-82.

Lynch WJ, Carroll ME (2000). Reinstatement of cocaine selfadministration in rats: sex differences. Psychopharmacology 148: 196-200.

Lynch WJ, Roth ME, Carroll ME (2002). Biological basis of sex differences in drug abuse: preclinical and clinical studies. Psychopharmacology 164: 121-137.

Lynch WJ, Roth ME, Mickelberg JL, Carroll ME (2001). Role of estrogen in the acquisition of intravenously self-administered cocaine in female rats. Pharmacol Biochem Behav 68: 641-646.

McEwen BS (2001). Genome and hormones: gender differences in physiology - invited review: estrogens effects on the brain: multiple sites and molecular mechanisms. J Appl Physiol 91: 2785-2801.

Mello NK (1995). Cocaine abuse and reproductive function in women. In: Wetherington CL, Roman AR (eds). Drug Addiction Research and the Health of Women. US Department of Health and Human Services: Rockville, MD. pp 131-150.

Mendelson JH, Mello NK, Sholar MB, Seigel AJ, Kaufman MJ, Levin JM et al (1999). Cocaine pharmacokinetics in men and in women during the follicular and luteal phases of the menstrual cycle. Neuropsychopharmacology 21: 294-303.

Pellis SM (2002). Sex differences in play fighting revisited: traditional and nontraditional mechanisms of sexual differentiation in rats. Arch Sexual Behav 31: 17-26.

Reisert I, Schuster R, Zienecker R, Pilgrim C (1990). Prenatal development of mesencephalic and diencephalic dopaminergic systems in the male and female rat. Dev Brain Res 53: 222-229.

Robbins SJ, Ehrman RN, Childress AR, O'Brien C (1999). Comparing levels of cocaine cue reactivity in male and female outpatients. Drug Alcohol Depend 53: 223-230.

Roberts DCS, Bennett SAL, Vickers G (1989). The estrous cycle affects cocaine self-administration on a progressive ratio schedule in rats. Psychopharmacology 98: 408-411.

Robinson TE (1984). Behavioral sensitization: characterization of enduring changes in rotational behavior produced by intermittent injections of amphetamine in male and female rats. Psychopharmacology (Berlin) 84: 466-475.

Robinson TE, Berridge KC (2000). The psychology and neurobiology of addiction: an incentive-sensitization view. Addiction 95: S91-S117.

Romeo RD, Diedrich SL, Sisk CL (2000). Effects of gonadal steroids during pubertal development on androgen and estrogen receptor-alpha immunoreactivity in the hypothalamus and amygdala. J Neurobiol 44: 361-368.

Thompson TL (1999). Attenuation of dopamine uptake in vivo following priming with estradiol benzoate. Brain Res 834: 164-167.

Weeks JR (1972). Long-term intravenous infusions. In: Meyers RD (ed). Methods in Psychobiology. Academic Press: London. Vol 2, pp 155-168.

Wise RA (1987). The role of reward pathways in the development of drug dependence. Pharmacol Ther 35: 227-263. 